Preprints of the

Max Planck Institute for

Research on Collective Goods

Bonn 2009/8

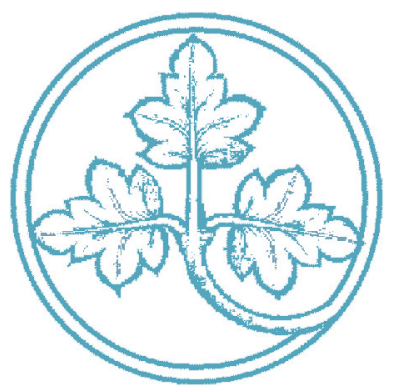

Leading with(out) Sacrifice? A Public-Goods Experiment with a Super-Additive Player

Andreas Glöckner

Bernd Irlenbusch

Sebastian Kube

Andreas Nicklisch

Hans-Theo Normann

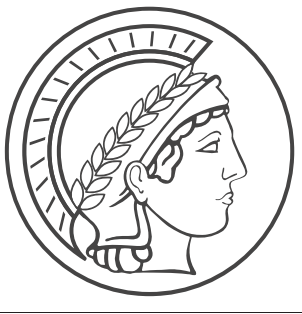




\title{
Leading with(out) Sacrifice? A Public-Goods Experiment with a Super-Additive Player
}

\author{
Andreas Glöckner \\ Bernd Irlenbusch \\ Sebastian Kube \\ Andreas Nicklisch \\ Hans-Theo Normann
}

März 2009 


\title{
Leading with(out) Sacrifice? \\ A Public-Goods Experiment with a Super-Additive Player $^{\dagger}$
}

\author{
Andreas Glöckner \\ Bernd Irlenbusch \\ Sebastian Kube \\ Andreas Nicklisch \\ Hans-Theo Normann
}

Max Planck Institute for Research on Collective Goods,

Kurt-Schumacher-Str. 10, 53113 Bonn, Germany.

email: [surname] @coll.mpg.de

\begin{abstract}
We analyse two team settings in which one member in a team has stronger incentives to contribute than the others. If contributions constitute a sacrifice for the strong player, the other team members are more inclined to cooperate than if contributions are strictly dominant for the strong player.
\end{abstract}

Keywords: Experiments, Leadership, Reciprocity, Voluntary Contribution Mechanism

JEL: C91, C92, H40, H41

$\dagger \quad$ We thank Michael Kurschilgen for useful comments. 


\section{Introduction}

Suppose several academics are working together on a research project. Usually, providing input to the joint project much resembles contributing to a public good, and therefore reciprocity and conditional cooperation may affect the team members. But now assume that for a certain team member, working on the project pays privately. For example, this researcher might have to accomplish a task required for the project (say, gathering data or acquiring knowledge about a new research method) for some closely related and profitable consultancy work anyway. How will the collaborators on the project respond to the work input of this team member? Will they regard it as an example to follow or rather neglect any reciprocity motive because of the private profitability of the work?

We analyse this situation by introducing a public-goods experiment where one player has a higher marginal per-capita rate of return (MPCR) from the public good than the others. In our baseline treatment, one player (a "super-additive" player) has an MPCR larger than one, i.e., she has a net benefit from contributing to the public good. ${ }^{1}$ In a control treatment, the distinguished player has a high per-capita rate but smaller than one, such that contributions are relatively cheap for this player but still constitute a sacrifice.

Our data show that the presence of a strong player with an MPCR smaller than one has a positive impact on the contributions of the other players. However, if the strong player has an MPCR larger than one, the other group members contribute less than in the comparison treatment, although the distinguished player contributes almost her entire endowment.

The results contribute to the literature on conditional cooperation and reciprocity. There is substantial evidence that subjects are conditional cooperators, i.e., they cooperate only if other players of the group do the same (Fischbacher et al. 2001). This robust finding has initiated publicgoods experiments in which group members choose sequentially. Some player becomes the first mover - either voluntarily or exogenously imposed - who can give a positive example to the other group members (Clarke and Sefton 2001; Gächter and Renner 2007; Potters et al. 2005, 2007; Güth et al. 2007; Levati et al., forthcoming). These studies find that participants indeed reciprocate to first movers who provide an example. Our results show that a leader's sacrifice (Choi, Mai-Dalton 1998; De Cremer, van Knippenberg 2005) considerably supports the emergence of this behaviour.

1 Zelmer (2003) reviews linear public-goods games with asymmetric marginal per capita rates of return, none of which involves players with a rate larger than one. 


\section{The Experiment}

\subsection{Experimental Design}

In our experiment, subjects participate in 2x10 periods of a typical linear public-goods game in constant groups of four players with a surprise restart ${ }^{2}$ after period 10. Each group consists of one player of type A and three players of type B. The subjects' types are randomly determined at the beginning and kept constant throughout the experiment. Players interact anonymously, but player types are common knowledge.

Players receive an endowment of 20 tokens per period and simultaneously decide how to share this endowment between their private and a joint group account. Subsequently, they are informed about the individual contributions of each player in the group and their own payoff. Players receive 1 point for each token they put in their private account. Additionally, all players in the group earn points for each token that is put in the group account either by themselves or by any other player. Players of type B receive 0.4 points per group account token. The MPCR for players of type A differs across treatments: In our main treatment [T 1.4] their MPCR equals 1.4, whereas it is 0.9 in our control treatment [T 0.9]. Consequently, player $i^{\prime}$ s individual period payoff, $\pi_{i}$, equals

$$
\pi_{i}=e_{i}-g_{i}+\left(0.4+0.5 \delta_{i}\right) \sum_{j} g_{j}
$$

where $e_{i}$ denotes player $i$ 's endowment, $g_{i}$ player $i$ 's contribution to the joint group account, and $\delta_{i}$ equals 1 if player $i$ is of type $\mathrm{A}$ in [T 0.9], $\delta_{i}$ equals 2 if player $i$ is of type $\mathrm{A}$ in the [T 1.4], and 0 otherwise. The computerised experiments ${ }^{3}$ were conducted at the EconLab at the University of Bonn in December 2007. We ran 4 sessions with a total of 21 matching groups (84 subjects), leaving us with 10 independent observations in treatment [T 0.9] and 11 independent observations in treatment [T 1.4]. At the beginning of each session, instructions were distributed and read out aloud. ${ }^{4}$ Afterwards, participants could pose clarifying questions in private and had to answer a set of control questions to ensure that everybody had understood the game. A session lasted for about 45 minutes. Points earned were accumulated over all periods and converted at an exchange rate of 1 Euro per 85 points. Subjects earned on average 10.93 Euro (standard deviation 1.78 Euro) including a show-up fee of 4 Euro. were kept constant across all periods (see Andreoni 1988 or Croson 1996 for similar restart-designs).

3 Subjects were recruited with the online recruiting system ORSEE (Greiner 2004), and the experimental software was developed with the zTree software package (Fischbacher 2007).

$4 \quad$ English translations of the German instructions are available from the authors upon request. 


\subsection{Behavioural Predictions}

In our control treatment [T 0.9 ], zero contributions are the unique subgame-perfect Nash equilibrium in each stage game of the finitely repeated linear public-goods game, if one assumes players who are rational and only interested in their own monetary payoff. Also players of type B in treatment [T 1.4] contribute nothing in the Nash equilibrium. Due to the MPCR being greater than one, A-players in [T 1.4] have a dominant strategy to contribute their entire endowment to the public good. Thus, under standard assumptions, we should expect to observe a treatment effect only in the decision of A-players.

Once we move away from the standard assumptions and introduce, e.g., reciprocity or conditional cooperation, B-players' behaviour might also be affected by the treatment manipulation. The high contributions of the super-additive player A in [T 1.4] could possibly motivate them to cooperate and contribute a substantial amount, too. However, if it is not A's contribution per se that matters, but rather the assumed underlying motivation, the incentive structure in [T 1.4] might hamper conditional cooperation - simply because high contributions of player A cannot be identified as being a clearly cooperative action. As a consequence, B-players might then be unsure about whether to reciprocate or not.

\subsection{Results}

Figure 1 illustrates the average contributions in both treatments and for both types of players.

Figure 1: Mean contributions by periods

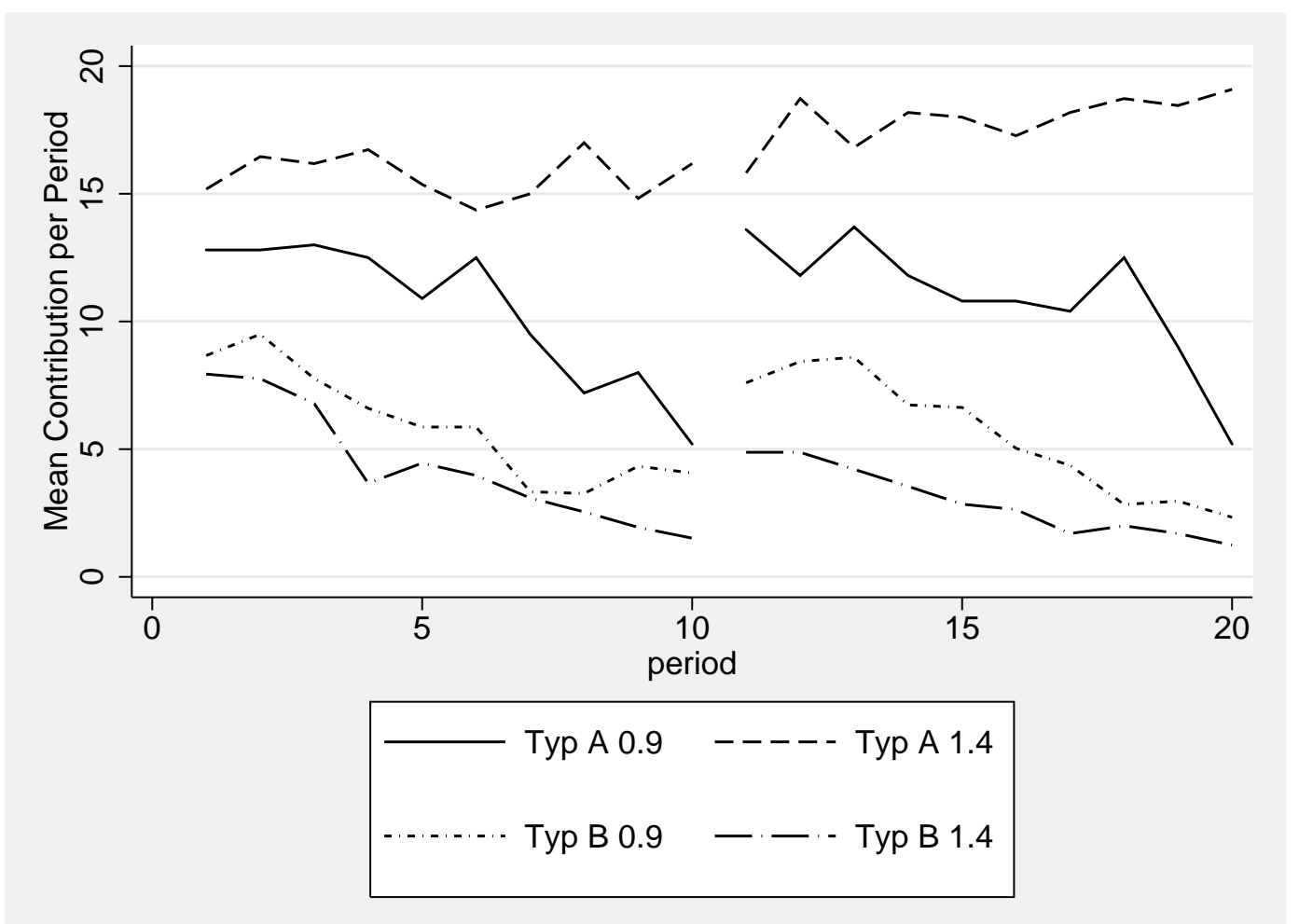


The effect of increasing the MPCR of player A is strong and significant. When their MPCR equals 1.4 instead of 0.9 , they contribute on average about $50 \%(40 \%)$ more in the first (second) phase of the experiment (rank sum test, $p=0.02$ and $p=0.01$, one-sided). The difference remains stable and significant over time (cp. Table 1).

By contrast, the contributions of players B are much higher in the absence of a super-additive player. Compared to treatment [T 1.4], players B contribute approximately 34\% (93\%) more to the public good in the first (second) phase of treatment [T 0.9]. Except for the beginning, this difference reaches significance over time (e.g., $p<0.05$, rank sum test on periods $11-20$, cp. Table 1).

Table 1: Contributions by periods

\begin{tabular}{c|ccccc}
\hline \hline Period & $\mathbf{1}$ & $\mathbf{1 - 5}$ & $\mathbf{6 - 1 0}$ & $\mathbf{1 0}$ & $\mathbf{1 - 1 0}$ \\
\hline Type A 0.9 & 12.8 & 12.4 & 8.5 & 5.2 & 10.4 \\
Type A 1.4 & 15.2 & 16.0 & 15.5 & 16.2 & 15.7 \\
Prob>|z| & 0.66 & 0.13 & 0.01 & 0.01 & 0.02 \\
\hline & $\mathbf{1 1}$ & $\mathbf{1 1 - 1 5}$ & $\mathbf{1 6 - 2 0}$ & $\mathbf{2 0}$ & $\mathbf{1 1 - 2 0}$ \\
\hline Type A 0.9 & 13.6 & 12.3 & 9.6 & 5.2 & 11.0 \\
Type A 1.4 & 15.8 & 17.5 & 18.3 & 19.1 & 17.9 \\
Prob>|z| & 0.43 & 0.02 & 0.01 & 0.01 & 0.01 \\
\hline & $\mathbf{1}$ & $\mathbf{1 - 5}$ & $\mathbf{6 - 1 0}$ & $\mathbf{1 0}$ & $\mathbf{1 - 1 0}$ \\
\hline Type B 0.9 & 8.7 & 7.7 & 4.2 & 4.1 & 5.9 \\
Type B 1.4 & 7.9 & 6.1 & 2.6 & 1.5 & 4.4 \\
Prob>|z| & 0.39 & 0.25 & 0.09 & 0.09 & 0.26 \\
\hline & $\mathbf{1 1}$ & $\mathbf{1 1 - 1 5}$ & $\mathbf{1 6 - 2 0}$ & $\mathbf{2 0}$ & $\mathbf{1 1 - 2 0}$ \\
\hline Type B 0.9 & 7.6 & 7.6 & 3.5 & 2.3 & 5.6 \\
Type B 1.4 & 4.9 & 4.1 & 1.9 & 1.2 & 2.9 \\
Prob>|z| & 0.22 & 0.13 & 0.08 & 0.28 & 0.05 \\
\hline \hline
\end{tabular}

Note: The table reports average contribution to the public good for treatment [T 0.9] and [ $\mathrm{T}$ 1.4] (first two rows). The third row reports $p$-values (two-sided) from a nonparametric Wilcoxon rank sum test

The tendency of higher contributions from B-players in [T 0.9] is despite the fact that players A contribute more in [T 1.4] than in [T 0.9]. Our data thus suggest that the unambiguousness of A's motivation to contribute is an important factor for conditional cooperation. This can also be seen by calculating a Spearman correlation coefficient between B-players' average contributions and player A's contribution in the previous period as a descriptive measure for each independent observation separately, and then comparing the coefficients between treatments. ${ }^{5}$ This descriptive measure of the reaction of B-players' contributions on the behaviour of A on average equals 0.18 in [T 0.9] and -0.07 in [T 1.4], the difference being significant (rank sum test, $p=0.04$, twosided). Correspondingly, after the A-player has contributed more than zero in the previous period

5 Three matching groups in 1.4 are excluded, because their players A always contributed their entire endowment, resulting in too many ties to calculate a correlation coefficient. 
the mean contribution of B-players is 6.1 in treatment [T 0.9], but only 3.7 in treatment [T 1.4]. In both treatments, B-players' contributions are more in line with the average contributions of the other B-players in the previous period (the average Spearman correlation coefficient is 0.27 in both treatments).

In treatment [T 0.9] we observe a typical restart effect, i.e., contribution levels in periods 1 and 11 are virtually the same. This is true for both player types. Yet, in treatment [T 1.4] - although A-players' contributions are relatively stable during the first 10 periods - players B exhibit a less cooperative attitude: in the second phase they start at a lower level than in the first phase (signed rank test, $p=0.07$, two-tailed, on average 7.94 in period 1 and 4.88 in period 11).

Total contributions to the joint group account do not differ between treatments (rank sum test, $p=0.95$ for the first ten periods, on average 28.2 in [T 0.9] and 28.8 in [T 1.4] and $p=0.48$ for the last ten periods, 27.6 in [T 0.9] and 26.8 in [T 1.4], both two-sided). Thus, the higher contributions of players A in [T 1.4] - due to the higher MPCR - are compensated by higher contributions of players $\mathrm{B}$ in [T 0.9]. Note that this ultimately depends on our parameterisation and would probably change if the number of B-players in the group were increased.

\section{Conclusion}

Our results refine the previous evidence on conditional cooperation in public-goods environments and show that others follow a high contributing player to a larger extent if they know that her example requires a sacrifice. However, if contributing can be attributed to a different motive, for example, individual payoff maximisation, others feel less inclined to follow the example. In this respect our findings underline the importance of intentions for cooperation (Blount 1995, Charness 2004, Falk et al., forthcoming) in public-goods environments also, confirming the intuition that a sacrifice provides an encouraging signal to followers (Hermalin 1998). Thus, a team member who has a personal motive to contribute, e.g., because it privately pays off for her to do so, might be well advised to disguise this fact and present her contributions as costly and truly cooperative choices in order to foster group cooperation. 


\section{References}

Andreoni, James (1988) Why free ride? Strategies and Learning in Public-Goods Experiments, Journal of Public Economics 37, 291-304.

Blount, Sally. (1995) When Social Outcomes Aren't Fair: The Effect of Causal Attributions on Preferences, Organizational Behavior and Human Decision Process 63, 131-144.

Charness, Gary (2004) Attribution and Reciprocity in an Experimental Labor Market, Journal of Labor Economics 22, 665-688.

Choi, Yeon, Mai-Dalton, Renate R. (1998) On the Leadership Function of Self-Sacrifice, Leadership Quarterly 9(4), 475-501.

Clarke, Kenneth and Martin Sefton (2001) The Sequential Prisoners Dilemma: Evidence on Reciprocation, Economic Journal 111, 51-68.

Croson, Rachel (1996) Partners and strangers revisited, Economic Letters 53, 25-32.

De Cremer, David, van Knippenberg, Daan (2005) Cooperation as a Function of Leader SelfSacrifice, Trust, and Identification, Leadership \& Organization Development Journal 26(5), 355-369.

Falk, Armin, Ernst Fehr and Urs Fischbacher, Testing Theories of Fairness - Intentions Matter, forthcoming in: Games and Economic Behavior

Fischbacher, Urs (2007) z-Tree: Zurich toolbox for ready-made economic experiments, Experimental Economics 10, 171-178.

Fischbacher, Urs, Simon Gächter and Ernst Fehr (2001) Are People Conditionally Cooperative? Evidence from a Public Goods Experiment, Economics Letters 71, 397-404.

Gächter, Simon and Elke Renner (2007) Leading by Example in the Presence of Free-Rider Incentives, Working Paper University of Nottingham.

Greiner, Ben (2004) An Online Recruitment System for Economic Experiments, In: Forschung und wissenschaftliches Rechnen 2003. GWDG Bericht. Vol. 63, edited by Kurt Kremer and Volker Macho, 79-93. Goettingen: Gesellschaft fuer Wissenschaftliche Datenverarbeitung, 2004.

Güth, Werner, Vittoria Levati, Matthias Sutter, Eline van der Heijden (2007) Leading by example with and without exclusion power in voluntary contribution experiments, Journal of Public Economics 91, 1023-1042.

Hermalin, Benjamin (1998) Toward an Economic Theory of Leadership: Leading by Example, The American Economic Review 88, 1188-1206. 
Levati, Vittoria, Matthias Sutter, Eline van der Heijden, Leading by example in a public goods game with heterogeneity and incomplete information, forthcoming in: Journal of Conflict Resolution.

Potters, Jan, Martin Sefton and Lise Vesterlund (2005) After You - Endogenous Sequencing in Voluntary Contribution Games, Journal of Public Economics 89, 1399-1419.

Potters, Jan, Martin Sefton and Lise Vesterlund (2007) Leading-by-example and signaling in voluntary contribution games: An experimental study, Economic Theory 33, 169-182.

Zelmer, Jennifer (2003) Linear public goods experiments: A meta-analysis, Experimental Economics 6, 299-310. 


\section{Appendix}

\section{Instructions for the experiment}

\section{(Treatment variations are indicated with \{\} )}

\section{General introductory information}

- Each participant is endowed with a starting capital of $\mathbf{3 4 0}$ points credited on his private account independent from the behaviour in the experiment.

- The experiment consists of two parts. In the following the course of action of the first part is explained. The instructions of the second part will be handed out later.

\section{Part 1}

\section{Course of action}

- During part 1, you belong to a group consisting of $\mathbf{4}$ participants. The identity of the other participants remains unknown to you. The composition of the group does not change. During part 1 of the experiment you will exclusively interact with the participants in your group.

- In each group there are two roles: one type A player and three type B players. The roles will be randomly awarded at the beginning and do not change.

- Part 1 consists of $\mathbf{1 0}$ periods.

As soon as you know your type, please write the type into the following box:

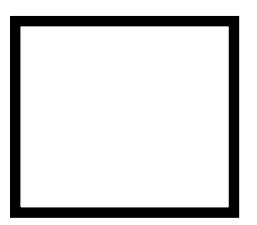

\section{Contribution to the common project}

In each period each group member receives an endowment of 20 points. You have to decide how many of the 20 points you want to contribute to a common project. You can keep the remaining points.

\section{Calculation of the payoff of a type A player in one period}

In a period your payoff consists of two components:

- $\quad$ tokens you keep = endowment - your contribution to the project

- $\quad$ earnings from the project $=1.4\{0.9\} \times$ sum of the contributions of all group members

Thus, if you are a type A player, your payoff is:

20 - your contribution to the project

$+1.4\{0.9\} \times$ sum of the contributions of all group members

Calculation of the payoff of a type $B$ player in one period In a period your payoff consists of two components:

- $\quad$ tokens you keep = endowment - your contribution to the project

- earnings from the project $=0.4 \mathrm{x}$ sum of the contributions of all group members 
Information at the end of a period

At the end of a period you will receive an overview of the contributions of each player in the current period.

\section{Total payoff}

The total payoff from the experiment is composed of the starting capital of 340 points plus the sum of payoffs from all 10 periods. At the end of the experiment your total payoff will be paid out to you, with an exchange rate of $1 €$ per 85 tokens.

\section{Please notice}

Communication is not allowed during the whole experiment. If you have any questions, please raise your hand. All decisions are made anonymously, i.e., no other participant is informed about the identity of someone who made a certain decision. The payment is anonymous too, i.e., no participant gets to know the payoff of another participant.

\section{Groups and roles}

\section{Part 2}

- You belong to the same group as in part 1. Also, during part 2 of the experiment you will exclusively interact with the participants in your group.

- You have the same role as in part 1.

\section{Periods and course of action in a period}

- Part 2 also consists of $\mathbf{1 0}$ periods.

- In each period in part 2 you also have to decide about your contribution to the common project.

- The calculations of payoffs and the information at the end of a period are also the same as in part 1 of the experiment.

- The payoff of a period is again added to your total payoff.

Table: Average contributions by group and periods

\begin{tabular}{cc|cccc|c|c|c|c|c|}
\hline \hline & Period & \multicolumn{6}{|c|}{$\mathbf{1 - 1 0}$} & \multicolumn{4}{c|}{$\mathbf{1 1 - 2 0}$} \\
\cline { 3 - 10 } & Type & A 0.9 & A 1.4 & B 0.9 & B 1.4 & A 0.9 & A 1.4 & B 0.9 & B 1.4 \\
\hline Group & 1 & 9 & 18 & 7.3 & 7.6 & 9.6 & 19 & 5.6 & 7.3 \\
& 2 & 13.3 & 12.1 & 3.6 & 5.6 & 12.4 & 14.7 & 4.1 & 2.3 \\
3 & 7 & 20 & 7.3 & 8.9 & 9.6 & 20 & 8.7 & 1.6 \\
4 & 11.8 & 20 & 10.5 & 9.7 & 8.5 & 20 & 4.7 & 6.3 \\
5 & 16 & 7.7 & 5.2 & 0.4 & 8 & 15.6 & 2.7 & 0.1 \\
6 & 14.7 & 16.9 & 3.4 & 2.8 & 18 & 19.9 & 7.8 & 3.9 \\
7 & 4.5 & 17.9 & 8.3 & 2.6 & 3.1 & 19.4 & 4.4 & 0.1 \\
8 & 17.2 & 5.1 & 6.4 & 3.8 & 18.8 & 8.9 & 2.9 & 3.6 \\
9 & 10.9 & 19.3 & 2.8 & 0.6 & 14.4 & 19.7 & 3.9 & 0 \\
10 & 0 & 20 & 4.4 & 4.6 & 7.2 & 20 & 10.6 & 7.4 \\
11 & & 16 & & 1.4 & & 16 & & 0.1 \\
\hline
\end{tabular}

